\title{
Karides ve Kerevit Yetiştiriciliğinde Prebiyotik Uygulamalar
}

\author{
Metin YAZICI ID Yavuz MAZLUM iD \\ İskenderun Teknik Üniversitesi/ Deniz Bilimleri ve Teknolojisi Fakültesi, İskenderun/HATAY \\ $\bowtie$ : metin.yazici@iste.edu.tr
}

\section{ÖZET}

Su ürünleri yetiştiriciliği, dünyadaki en hızlı büyüyen ve gelecek vadeden besin üretim sektörlerinden biridir. Ticari su ürünleri yetiştiriciliğinde, yetiştiriciliği yapılan türlerin hastalık direncini, yem verimliliğini ve büyüme performansını arttırmak çok önemlidir. Bunlar gerçekleşirse, genel üretim maliyetleri dikkate değer ölçüde azalır. Enfeksiyon hastalıklarını azaltmak veya büyüme performansını arttırmak için su ürünleri yetiştiriciliğinde antibiyotik kullanımı yaygın olarak uygulanmıștır. Bununla birlikte su ürünleri yetiştiriciliğinde antibiyotiklerin ve bazı kimyasal ilaçların ayırım yapılmadan rastgele kullanılması, insan sağlığının yanı sıra çevre üzerinde de potansiyel olumsuz etkilere yol açmıştır. $\mathrm{Bu}$ yüzden prebiyotikler, probiyotikler ve sinbiyotiklerinde dahil olduğu fonksiyonel yem katkıları, balık ve eklembacaklı sağlığını iyileştirmek için çevre dostu yöntemler olarak önem kazanmıştır. Bu derleme de prebiyotiklerin etkilerine odaklanılmıştır. Prebiyotikler; sindirim sisteminde doğal olarak bulunan yararlı bakterilerin aktivitesini ve büyümesini uyararan ve patojenik olanları ortamdan uzaklaştırarak hayvan organizmasını olumlu yönde etkileyebilen sindirilemeyen besin bileşenleridir. Çeşitli karasal hayvanlarda ve balıklarda sağlık ve büyüme performansı üzerine potansiyel faydaları belirtilmesine rağmen, eklembacaklı prebiyotiklerin kullanımı daha az araştırılmıştır. $\mathrm{Bu}$ derlemenin amacı, prebiyotiklerin karides ve kerevit yetiştiriciliğinde büyüme performansı, hayatta kalma oranı, sindirim enzim aktiviteleri ve barsak morfolojisi üzerindeki etkilerini değerlendirmektir. Bu tür uygulamalarda en yaygin kullanılan prebiyotikler, mannanoligosakkaritler (MOS), fruktooligosakkaritler (FOS), GOS (galaktooligosakkarit), izomaltooligosakkaritler (IMO), ksiloligosakkaritler (XOS), inülin ve bazı ticari prebiyotiklerdir.

\section{Prebiotic Applications in Cultured Crayfish and Shrimps}

\section{ABSTRACT}

Aquaculture is one of the fastest growing and promising sectors of food production all over the world. In commercial aquaculture, it is very important to elevate disease resistance, feed efficiency and growth performance of cultured aquatic species. If these are realized, overall production costs would be remarkably reduced. Antibiotics has been widely used in aquaculture to alleviate infectious diseases or to promote growth performance. On the other hand, indiscriminate use of antibiotics and some chemical drugs in aquaculture has led to potential negative effects on the environment as well as human health. Therefore, functional dietary supplements, such as prebiotics, probiotics and synbiotics have been increasing importance as an environment friendly method to improve the health of fish and crustaceans. In this review, the effects of prebiotics are focused. Prebiotics are nondigestible feed ingredients that can positively affect the animal organism by stimulating the activity and growth of beneficial native bacteria in the gastrointestinal tract and

\section{Makale Tarihçesi}

Geliş Tarihi: 17.10.2018

Kabul Tarihi : 19.11.2018

\section{Anahtar Kelimeler}

mos,

sindirim sistemi,

büyüme,

akuakültür,

barsak morfolojisi

\section{Derleme Makalesi}

\section{Article History}

Received : 17.10.2018

Accepted : 19.11.2018

\section{Keywords}

mos,

digestive system,

growth, aquaculture, gut morphology

\section{Review Article}


eliminate the pathogenic ones. Despite the potential benefits to health and growth performance as noted in various terrestrial animals and fish, the use of prebiotics in crustacean has been less investigated. The purpose of this review is to discuss the effects of dietary prebiotics on growth performance, survival rate, digestive enzyme activities and intestinal morphology in shrimp and crayfish cultivation. The most commonly used prebiotics in such applications are mannanoligosaccharides (MOS), fructooligosaccharides (FOS), GOS (galactooligolosaccharide), isomaltooligosaccharides (IMO), xylooligosaccharides (XOS) and inulin.

To cite: Yazıcı M, Mazlum Y 2019. The Karides ve Kerevit Yetiştiriciliğinde Prebiyotik Uygulamalar. KSÜ Tar Doğa Derg 22(1) : 153-163, DOI : 10.18016/ ksutarimdoga.vi.471559.

\section{GIRISS}

Tüketici bilincinin artması ve gıda güvenliği, su ürünleri yetiştiriciliğinde verimliliğin sağlıklı ürün eldesi yönünde arttırılması gerektiğini savunan çeşitli çalışmalara hız kazandırmıştır (Daniels ve Hoseinifar, 2014). 2016 yılı verilerine göre su ürünleri sektöründe 171 milyon ton toplam su ürünleri üretiminin 80 milyon tonu yetiştiricilikten elde edilmiştir (FAO 2018). Su ürünleri yetiştiriciliğinde karides ve kerevit gibi eklembacaklıların üretimi, 7.9 milyon ton ile balık ve kabuklulardan (mollusk) sonra 3. büyük üretim grububunu oluştururken, ekonomik değer bakımından 57.1 milyar dolarlık gelirle balıklardan sonra 2. büyük grubu oluşturmaktadır (Çizelge 1).

Çizelge 1. 2016 su ürünleri yetiştiricilik değerleri (FAO, 2018)

\begin{tabular}{lcccc}
\hline Yetiştiricilik grupları & $\begin{array}{c}\text { Üretim } \\
\text { (milyon ton) }\end{array}$ & $\begin{array}{c}\text { Üretim } \\
\text { (\%) }\end{array}$ & $\begin{array}{c}\text { Ekonomik değeri } \\
\text { (milyar dolar) }\end{array}$ & $\begin{array}{c}\text { Ekonomik değeri } \\
\text { (\%) }\end{array}$ \\
\hline Balık & 54.1 & 68 & 138.5 & 60 \\
Kabuklu & 17.1 & 21 & 29.2 & 12 \\
Eklembacaklı & 7.9 & 10 & 57.1 & 25 \\
Diğerleri & 0.94 & 1 & 6.8 & 3 \\
\hline
\end{tabular}

Eklembacaklı su ürünleri üretiminin geliştirilmesi, genel su ürünleri üretimini de arttırmıştır. Hatta tüketici taleplerinin yetiştiricilikten karşılanmasıyla doğal stoklar üzerindeki av baskısının da azalacağ ileri sürülmektedir. Ancak dünya çapında artan yetiştiricilik, sanayi ve kentleşme genel olarak su kalitesinin bozulmasina, stresin ve bakteriyel yükün artmasına neden olmaktadır. $\mathrm{Bu}$ durum, üretimde azalmaya ve bulaşıcı hastalıklardan kaynaklı kayıplara yol açmaktadır (Mona ve ark., 2015). Hastalıklar, ticari su ürünleri yetiştiriciliğinin gelişmesinde en büyük problemlerden biridir (Miandare ve ark., 2017).

Balık yetiştiriciliğinde olduğu gibi karides ve kerevit yetiştiriciliğinde de bakteriyel hastalıkların tedavisinde geniş spektrumlu antibiyotikler yoğun bir şekilde kullanılmıştır (Miandare ve ark., 2017; Hoseinifar ve ark., 2017). Antibiyotiklerin sürekli ve bilinçsiz kullanımını sonucu antibiyotiklere karşı bakterilerde direnç gelişimi ortaya çıkmış, buna ilaveten hayvansal dokularda da antibiyotik birikimi görülmüştür. Antibiyotiklerin çevreye ve insana zarar verme potansiyellerinden dolayı balıklarda ve kabuklularda yem katkı maddesi olarak kullanılması yasaklamış ve diğer kullanımlarına da ciddi sinırlamalar getirilmiştir. Bu yüzden akuakültürde hastalıkların kontrolü ve sağlığın geliştirilmesi için kemoteropotik olmayan prebiyotik, probiyotik, immunostimulan, aşı, ve bitkilerden elde edilen doğal tedavi maddeleri gibi alternatif stratejilerin kullanılmasına acil ihtiyaç duyulmuştur (Yazıcı ve Candan, 2006; Genç ve Kaya, 2017; Hoseinifar ve ark.2017; Sivasankar ve ark.,2017; Yazıcı, 2017; Elshopakey ve ark., 2018).

$\mathrm{Bu}$ alternatif stratejilerden biri olan probiyotiklerin yem ürünlerinde ve sindirim siteminde canlığını koruma ve sindirim sisteminde kolonize olabilme gibi bazı sınırlamaları nedeniyle, prebiyotikler ön plana çıkmıştır. Prebiyotikler; sindirim sistemindeki bir veya sınırlı sayıdaki bakterinin gelişmesini ve/veya aktivitesini seçici bir şekilde uyararak yetiştiriciliği yapılan türe faydalı bir etki sağlayan sindirilemeyen besin bileşenleridir. Böylece konakçı sağlığı düzelmektedir (Roberfroid, 2007). Prebiyotikler balık sağlığını koruma ve geliştirmelerinin yanısıra doğal yem katkı maddeleri oldukları için yeme katıldıklarında özel önlemler almayı gerektirmez (Denev ve ark., 2009, Genç ve ark., 2011).

Bugüne kadar yapılan çalışmalarda prebiyotiklerin, yem dönüşümünde, bağışıklık sisteminde ve / veya stres toleransında iyileşme sağlayarak kabukluların büyümesinde ve hayatta kalma oranının 
arttırılmasında önemli bir potansiyele sahip olduğu gösterilmiştir (Sang ve ark., 2011; Mazlum ve ark., 2011; Huynh ve ark., 2017, 2018; ). Bunun yanısira, sindirim sistemi morfolojisinin geliştirilmesi, sindirim sistemindeki mikrobiyotanın düzenlenmesi ve sindirim sistemindeki sindirim enzimi aktivitelerinin arttırılması üzerine çeşitli çalışmalar yapılmıştır (Safari ve ark., 2014; Safari ve Paolucci, 2017a,b).

$\mathrm{Bu}$ derlemenin amacı, karides ve kerevit yetiştiriciliğinde kullanılan prebiyotik türlerin organizmanın büyüme performansı, hayatta kalma, sindirim enzim aktiviteleri ve barsak morfolojisine etkilerini ortaya koymaktır. Karides yetiştiriciliği
Dünya'da hızlı bir gelişme göstererek su ürünleri yetiştiriciliğinde önemli bir yer almıştır (Çizelge 1). Araştırmaların önemli bir kısmı penaeid karides yetiştiriciliği endüstrisinin büyüklüğü, pazar değerinin yüksek oluşu, tüm kabuklu yetiştiriciliğinin yarısından fazlasinı oluşturmasından dolayı çoğunlukla paneidler üzerinde yapılmıştır (Çizelge 2). Yetiştiriciliği yapılan karides türleri arasında beyaz karides (Litopenaeus vannamei), dev kaplan karidesi (Penaeus monodon) ve kuruma karidesi (Marsupenaeus japonicus) gibi türler ön plana çlkmaktadır (Elshopakey ve ark., 2018).

Çizelge 2 Yetiştiriciliği yapılan eklembacaklı türleri, üretim miktarı ve yüzdesi (FAO, 2018)

\begin{tabular}{lll}
\hline Yetiştiriciliği yapılan krustase türleri & Üretim miktarı Milyon ton & Üretim miktarı \\
\hline Beyaz karides, Litopenaeus vannamei & 4156 & 52.86 \\
Kırmızı kerevit, Procambarus clarkii & 920 & 11.70 \\
Cin yengeci, Eriocheir sinensis & 812 & 10.33 \\
Dev kaplan karidesi, Penaeus monodon & 701 & 8.91 \\
Oriental nehir karidesi, Macobrachium nipponense & 273 & 3.47 \\
Dev tatlısu karidesi, Macrobrachium rosenbergii & 234 & 2.98 \\
Diğer Eklembacaklllar & 767 & 9.76 \\
Eklembacaklılar toplam & 7862 & - \\
\hline
\end{tabular}

Prebiyotik Kullanımının Büyüme Performansı ve Hayatta Kalma Üzerine Etkileri

Karides ve kerevit yetiştiriciliğinde en çok kullanılan prebiyotikler; Mannanoligosakkarit (MOS), Fruktooligosakkarit (scFOS ve FOS), İsomaltooligosakkarit (IMO), Ksilooligosakkarit (XOS) ve Inülin gibi oligosakaritlerin yanısıra bazı ticari prebiyotikler (Grobiotik A, İmmunojen, Previda) olduğu gözükmektedir (Li ve ark., 2009; Anuta ve ark., 2016; Miandare ve ark., 2017; Motamedi-Sedeh ve ark., 2017). Günümüze kadar yapılan çalışmalar prebiyotik maddelerin direk yemlere ilavesi (Genç ve ark., 2007; Genç ve ark. 2011; Mazlum ve ark., 2011; Safari ve ark., 2017; Elshopakey ve ark., 2018), probiyotiklerle birlikte verilmesi (Partida-Arangure ve ark., 2013; Hoseinifar ve ark., 2015; Safari ve ark., 2017; Safari ve Paolucci, 2017a,b; Huynh ve ark., 2018) veya artemia ve rotifer gibi canlı yemler ile birlikte verilmesi şeklinde uygulanmıştır (Daniels ve ark., 2010; Hoseinifar ve ark., 2015; Widanarni ve ark., 2018).

Su ürünleri yetiştiriciliğinde prebiyotiklerle yapılan çalışmalarda, prebiyotiklerin büyüme ve hayatta kalma oranını arttırdığı, yem dönüşümünü iyileştirdiği, bağışıklığı güçlendirdiği, hastalık direncini arttırdığ 1 ve strese karşı toleransı yükselttiğini göstermiştir. $\mathrm{Bu}$ faydalar; sindirim sisteminde mikrobiyotayı düzenler ve sistemdeki yapıları fiziksel olarak güçlendirir şeklinde sunulmuştur. Bunun sonucu olarak, yetiştiriciliği yapılan organizmaların yem dönüştürme oranını iyileştirerek büyümesine katkı sağladığı bildirilmektedir (Ringo ve ark.2010; Sivasankar ve ark.2017; Hoseinifar ve ark.2017).

Prebiyotik çalışmaların ana hedeflerinden biri su ürünleri yetiştiriciliğinde doğrudan iyileşmeler sağlamaktır. Prebiyotik kullanımının karides ve kerevitlerde büyüme ve hayatta kalma konusunda iyileştirmeler sağladığı belirtilmiştir (Mona ve ark., 2015, Safari ve ark., 2017; Widanarni ve ark., 2018). Bazı kerevit ve karides türlerinde prebiyotik ilavesinin büyüme performansına ve hayatta kalma üzerine etkileri Çizelge 3 'te gösterilmiştir.

Saccharomyces cerevisiae türü maya hücresinin hücre duvarından elde edilen MOS, su ürünleri yetiştiriciliğinde en çok kullanılan prebiyotiktir. Balıklarla karşılaştırıldığında, kabuklular üzerine nispeten az çalışma yapılmasına rağmen, MOS ilaveli diyetlerde canlılarm farklı gelişim evrelerinde büyümeyi ve hayatta kalmayı iyileştirdiği gösterilmiştir (Aktaş ve ark., 2014; Genç ve ark., 2017). MOS, yeme ilave edildiğinde tatlı su kerevitlerinden Cherax destructor'da spesifik büyüme oranı (SGR) ve ortalama ağırlıkta artış sağladığı gösterilmiştir (Sang ve ark., 2011). Benzer sonuçlar, post larva yeşil kaplan karidesinde (Penaeus semisulcatus) (Genç ve ark., 2007), jüvenil siyah kaplan karidesinde (Penaeus monodon) (Sang ve ark., 2014) ve batı kral karidesinde (Penaeus latisulcatus) (Hai ve Fotedar, 2009 ) görülmüştür. Bununla birlikte, Mazlum ve ark., (2011) tarafindan tatlısu kerevitleri (Astacus leptodactylus) üzerine yapılan bir araştırmada, yeme farklı dozlarda ilave edilen MOS'un $\left(0,1.5,3.0\right.$ ve $\left.4.5 \mathrm{~g} \mathrm{~kg}^{-1}\right)$ deneme grupları 
arasında canlı ağırlık ve yem değerlendirme oranı (YDO) bakımından önemli bir değişiklik gerçekleştirmediği bildirilmiştir. Safari ve ark., (2014) tarafindan A. leptodactylus ile yapılan bir çalışmada; prebiyotik içeren yemlerle beslenen grupların tamamında elde ettikleri büyüme performansı verilerinin kontrol grubundan daha yüksek olduğunu bildirmiştir. Farklı dozlardaki MOS katkısı ile FOS'tan daha yüksek SBO (spesifik büyüme oranı) ve daha düşük YDO oranı elde edildiği de gösterilmiştir. $\mathrm{Bu}$ iki prebiyotik birlikte verildiğinde (2.25 g MOS + $1.5 \mathrm{~g}$ FOS $\mathrm{g}, \mathrm{kg}^{-1}$ yem) SBO, YDO ve hayatta kalma oraninda (HKO) tek tek verilmesinden daha iyi sonuçlar elde edildiği de vurgulanmıştır.

Çizelge 3. Bazı kerevit ve karides türlerinde prebiyotiklerin büyüme ve hayatta kalma oranı üzerine etkileri

\begin{tabular}{|c|c|c|c|c|c|c|c|c|c|}
\hline \multirow[t]{2}{*}{ Doz } & \multirow[t]{2}{*}{ Tür } & \multirow[t]{2}{*}{ Gün } & \multicolumn{2}{|c|}{ YDO (\%) } & \multicolumn{2}{|c|}{$\begin{array}{l}\text { SBO } \\
\text { (\%/gün) }\end{array}$} & \multicolumn{2}{|c|}{ HKO (\%) } & \multirow[t]{2}{*}{ Kaynak } \\
\hline & & & $\mathrm{K}$ & $\mathbf{P}$ & $\mathrm{K}$ & $P$ & $\mathrm{~K}$ & $\mathbf{P}$ & \\
\hline $3 \mathrm{~g}$ MOS & & 60 & 2.02 & 1.93 & 0.86 & 1.37 & 50 & 46.6 & Mazlum ve ark., 2011 \\
\hline $\begin{array}{ll}2.25 \mathrm{~g} & \mathrm{MOS}+1.5 \mathrm{~g} \\
\text { FOS } & \end{array}$ & & 126 & 3.31 & 2.67 & 0.86 & 1.59 & 73.2 & 94.1 & Safari ve ark.,2014 \\
\hline 10g GOS+Enf & Astacus & 126 & 3.11 & 2.13 & 1.59 & 2.19 & 43 & 96.6 & Safari ve paolucci, $2017 \mathrm{a}$ \\
\hline $10 \mathrm{~g} \mathrm{XOS+EnF}$ & & 126 & 3.83 & 2.13 & 0.78 & 1.53 & 44 & 95.6 & Safari ve Paolucci, 2017b \\
\hline 10g GOS + EnF & & 126 & 3.42 & 2.92 & 1.43 & 2.68 & 44 & 93.7 & Safari ve ark., 2017 \\
\hline $20 \mathrm{~g}$ GOS & & 97 & $\mathrm{~b}$ & $\mathrm{~b}$ & 0.33 & 0.42 & 77 & 75 & Nedaei ve ark., 2019 \\
\hline $\begin{array}{l}10 \mathrm{~g} \text { FOS } \\
\mathrm{Na} \text { alginate }\end{array}$ & $\begin{array}{l}\text { Procambarus } \\
\text { clarkii }\end{array}$ & $\begin{array}{l}30 \\
42\end{array}$ & $\begin{array}{l}\mathrm{b} \\
\mathrm{b}\end{array}$ & $\begin{array}{l}\mathrm{b} \\
\mathrm{b}\end{array}$ & $\begin{array}{l}\mathrm{b} \\
0.2\end{array}$ & $\begin{array}{l}\mathrm{b} \\
0.34\end{array}$ & $\begin{array}{l}93.8 \\
40\end{array}$ & $\begin{array}{l}95 \\
70\end{array}$ & $\begin{array}{l}\text { Dong ve Wang, } 2013 \\
\text { Mona ve ark., } 2015\end{array}$ \\
\hline 4 g MOS & $\begin{array}{l}\text { Cherax } \\
\text { destructor }\end{array}$ & 56 & $\mathrm{~b}$ & $\mathrm{~b}$ & 0.32 & 0.47 & 66.6 & 83.3 & Sang ve ark., 2011 \\
\hline $4 \mathrm{~g}$ FOS & $\begin{array}{l}\text { Macrobrachiu } \\
\text { m rosenbergii }\end{array}$ & 56 & $\mathrm{~b}$ & $\mathrm{~b}$ & 4.18 & 4.34 & $\mathrm{fb}$ & $\mathrm{fb}$ & Chen ve ark., 2017 \\
\hline $3 \mathrm{~g} \mathrm{MOS}$ & & 48 & 3.59 & 2.92 & 3.09 & 3.68 & 42.7 & 64 & Genc ve ark. 2007 \\
\hline $\begin{array}{l}5 \mathrm{~g} \quad \mathrm{MOS}+5 \mathrm{~g} \text { inulin } \\
\mathrm{kg}^{-1}\end{array}$ & & 28 & $\mathrm{~b}$ & $\mathrm{~b}$ & 1.21 & 1.8 & 87.7 & 95.8 & Li ve ark., 2018 \\
\hline $1.5 \mathrm{~g}$ mmunojen & & 60 & 1.68 & 1.65 & 2.12 & 2.23 & $\mathrm{~b}$ & $\mathrm{~b}$ & Miandare ve ark.,2017 \\
\hline MOS $12 \mathrm{mg} \mathrm{L}^{-1}$ & Litopenaeus & 15 & $\mathrm{~b}$ & $\mathrm{~b}$ & 25 & 37 & 67 & 91 & Widanarni ve ark., 2018 \\
\hline $2 \mathrm{~g} \mathrm{MOS}$ & vannamei & 56 & 1.78 & 1.44 & 2.29 & 2.59 & 100 & 99.3 & Zhang ve ark., 2012 \\
\hline $1.0 \mathrm{~g}$ previda & & 35 & 1.6 & 1.5 & 0.21 & 0.22 & 95.4 & 97.9 & Anuta ve ark., 2016 \\
\hline 20 g Grobiotic-A & & 42 & $\mathrm{~b}$ & $\mathrm{~b}$ & 0.3 & 0.3 & 95.9 & 96.5 & Li ve ark., 2009 \\
\hline $0.4 \mathrm{~g}$ inulin & & 62 & $\mathrm{~b}$ & $\mathrm{~b}$ & 3.2 & 3.1 & 96 & 100 & $\begin{array}{l}\text { Partida-Arangure ve ark., } \\
2013\end{array}$ \\
\hline
\end{tabular}

YDO:Yem değerlendirme oranı; SBO:Spesifik büyüme oranı; HKO: Hayatta kalma oranı; K:Kontrol; P:Prebiyotik katkılı grup; fb: fark yoktur.

MOS'un 2 ve $4 \mathrm{~g} \mathrm{~kg}^{-1}$ yeme ilavesinin Cherax tenuimanus kereviti için (Sang ve ark., 2009, 2011), 2, 4,6 ve $8 \mathrm{~g} \mathrm{~kg}^{-1}$ oranında $L$. vannamei için (Zhang ve ark., 2012) ve 3 ve $4.5 \mathrm{~g} \mathrm{~kg}^{-1}$ MOS düzeyinin ise $P$. semisulcatus karidesi için (Genç ve ark., 2007) hayatta kalma oranını arttırdığını bildirmişlerdir. Bu çalışmaların aksine, $5 \mathrm{~g} \mathrm{~kg}^{-1}$ MOS ilavesinin kral karideslerin hayatta kalma oranını etkilemediği anlaşlmıştır (Hai ve Fotedar 2009). Alternatif prebiyotik kaynağ 1 olarak kurutulmuş Hindistan cevizinden elde edilen MOS ile beslenen beyaz karideslerde hayatta kalma oranında artış olduğu bildirilmiştir (Rungrassamee ve ark., 2014; Rodrigues ve ark., 2018).

Genç ve ark. (2007), $3 \mathrm{~g} \mathrm{~kg}^{-1}$ MOS ilavesi ile beslenen yeşil kaplan karideslerdeki büyüme ve yem değerlendirme oranının istatistiki olarak önemli ve daha iyi olduğunu da vurgulamışlardır. Histolojik inceleme bulgularma göre ise MOS'un farklı seviyelerinin hepatopankreas doku üzerine olumsuz bir etki yaratmadığını ifade etmişlerdir.

Widanarni ve ark. (2018), MOS ile zenginleştirilmiş Artemia naupliileri yaklaşık ağırlıkları $0.25 \mathrm{~g}$ olan Litopenaeus vannamei post larvalarma 8 hafta süreyle farklı oranlarda vermiştir. Çalışma sonunda $12 \mathrm{mg} \mathrm{L}^{-1}$ MOS ile sindirim kapasitesinde, büyümede, hayatta kalma oranında artış elde edildiğini bildirmiştir. Ayrica post larvaların (penaeid karideslerde şiddetli enfeksiyonlara ve akut ölümlere neden olan patojen bir bakteri olan) Vibrio harveyi ile deneysel enfeksiyonunda MOS katkısının, bağışıklıkta artış gerçekleştirdiği bildirilmiştir. En yüksek büyüme performansı $12 \mathrm{mg}$ MOS ilave edilmiş yemle beslenen karideslerde bulunmuştur.

$\mathrm{Li}$ ve ark. (2018), pasifik beyaz karideste ( $L$. vannamei) İnulin ve MOS prebiyotiğinin birlikte ve 
ayrı ayrı çeşitli oranlarda (2,5, 5, $\left.10 \mathrm{mg} \mathrm{g}^{-1}\right)$ verilmesinin büyüme, immun bağlantılı gen ekspresyonu, beyaz benek sendromu virüsü (WSSV) ve Vibrio alginolyticus bakterisine karşı direnç etkisini araştırmışlardır. 28 gün süren çalışmanın sonunda hem tek tek hem de birlikte verilen MOS ve İnulin, karideslerde büyüme performansinda ve çeşitli immun bağlantılı gen ekspresyonunda artışa yol açmıştır. İnulin ve MOS'un birlikte verilmesi; karideslerin sindirim sistemindeki faydalı bakterilerin büyümesini arttırarak veya direk olarak spesifik olmayan bağışıklık sistemini aktive etmiştir. Bunun sonucunda WSSV ve $V$. alginolyticus enfeksiyonlarına karşı daha yüksek oranda direnç gelişimi sağlandığını bildirmişlerdir. Elde ettikleri sonuçlar ışı̆̆ında yemde $5 \mathrm{mg} \mathrm{g}^{-1}$ yem MOS ve $5 \mathrm{mg} \mathrm{g}^{-1}$ İnulin'in birlikte kullanımının karideslerde immunostimulan etki gösterebileceğini öne sürmüşlerdir.

Kerevit beslemesinde sinbiyotik uygulamaların (prebiyotik ve probiyotiklerin birlikte verilmesi) prebiyotik ve probiyotiklerin tek tek verilmesinden daha etkili olduğu öne sürülmüştür. Safari ve ark. (2017), ağırlıkları $11 \mathrm{~g}$ olan kerevit yemlerine MOS, XOS prebiyotiği (10 $\mathrm{g} \mathrm{kg}^{-1}$ oranlarında), Enterococcus faecalis (EnF) ve Pediococcus acidilactici (PeA) probiyotiklerini hem tek tek hemde birlikte katarak 126 gün çalışmayı yürütmüşlerdir. Bu prebiyotiklerin $(\mathrm{XOS}+\mathrm{EnF}, \mathrm{MOS}+\mathrm{PeA})$ birlikte verilmesiyle büyüme performansinda ve antioksidan parametrelerde artış olduğunu göstermişlerdir. Büyüme performansı üzerine etkilerine bakıldığında XOS + EnF' in birlikte verilmesinin diğer gruplardan daha yüksek olduğu bildirilmiştir. Bu çalışmanın astacid kerevit yetiştiriciliğinde hayatta kalma oranında ve büyüme performasında artışa bağlı olarak yeni araştırma alanları açabileceğini öne sürmüşlerdir (Safari ve ark., 2017). Astacus leptodactylus kerevitlerine yönelik diğer çalışmalar da Safari ve Paolucci (2017a, b) tarafindan gerçekleş̧tirilmiştir. Bu çalışmalarda GOS ve MOS prebiyotiklerinin hem tek tek hemde Enterococcus faecalis probiyotiğiyle birlikte verilmesinin (GOS +Enf) daha önceki çalışmasıyla kıyaslandığında büyüme performansında benzer şekilde artışların olduğunu göstermişlerdir (Çizelge 3).

FOS prebiyotiği tatlısu karidesi Macrobrachium rosenbergii post larvalarma farklı oranlarda (\% 0.1 , $0.4,1,2) 8$ hafta süreyle verildiğinde en yüksek SBO $\% \quad 0.4$ FOS katkll yemle beslenen gruplarda gözlenmiştir. Daha yüksek seviyelerde (\% 1.2) FOS kullanımının ise hepatopankreasta anormallikler oluşturarak oksidatif strese yol açtığ bildirilmiştir (Chen ve ark., 2017). Sınırlı sayıda çalışma yapılan IMO prebiyotiği tek başına kullanıldığında $L$. vannamei' de hayatta kalma oranlarını etkilemediği bildirilmiştir (Daniels ve Hoseinifar, 2014)
Inulin'in beyaz karideslerde ( $L$. vannamei) tek tek (Luna-Gonzales ve ark., 2012) veya probiyotik (Bacillus subtilis) ile verildiğinde büyüme performansı ve hayatta kalma üzerine etkilerinin

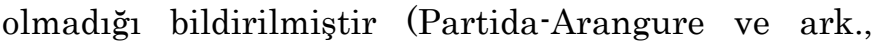
2013). Inulin ile yapılan başka bir çalışmada ise zenginleştirilmiş artemialarla beslenen Hint beyaz karides (Fenneropenaeus indicus) post larvalarinda hayatta kalma oranında kontrol grubuna göre önemli farklar bulunmuştur (Hoseinifar ve ark., 2015). Hoseinifar ve ark., (2010), Fenneropenaeus indicus larvaları ve post larvalarında bir ticari inülin kaynağı olan (Raftiline ST) uygulamışlardır. Karides larvalarının ya da post larvanın büyümesinde ve hayatta kalmasında inulin miktarının belirgin bir etkisinin olmadığını gözlemlemişlerdir.

İnülin'le olduğu gibi XOS'ta ilgili çalışmalar da kabuklularda sinırlı düzeydedir. XOS'un farklı oranlarda $\left(0.1-0.5 \mathrm{~g} \mathrm{~kg}^{-1}\right)$ yeme ilavesinin yem dönüşümünü iyileştirdiği ve $0.1 \mathrm{~g} \mathrm{~kg}^{-1}$ oranında verildiğinde ise karidesin vücut proteinini arttırdığ bildirilmiştir (Wang ve ark., 2010).

Çalışmalarda GOS prebiyotiğinin tek başına veya probiyotiklerle birlikte verilerek kullanıldığında, çeşitli balık türlerinde büyüme performansı, sindirim

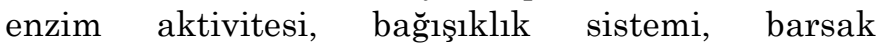
mikrobiyotası, barsak morfolojisi, hastalık ve stres direnci üzerine olumlu sonuçlar gösterdiği bildirilmiştir. Son zamanlarda GOS'un karides ve kerevitler üzerine etkisinin araştırılmasına yönelik bazı çalışmalar da yapılmıştır (Safari ve Paolucci, 2017a,b; Huynh ve ark., 2018; Nedaei ve ark., 2019).

GOS prebiyotiği Lactobacillus plantarum probiyotiğiyle birlikte karideslere verildiğinde bağışıklık sisteminde ve hastalık direncinde artış elde edilmiştir (Huynh ve ark., 2018). Nedaei ve ark. (2019), A. leptodactylus ile yaptıkları bir çalışmada yemlere GOS ilavesinin büyüme performansı ve hayatta kalma üzerine bir etki göstermediğini bildirmiştir. Fakat Safari ve Paolucci (2017b), prebiyotik, probiyotik ve sinbiyotik katkılı yemle kerevitleri beslediğinde büyüme performansı, hayatta kalma oranı ve besin verimliliği indisinde kontrol grubuna göre önemli ölçüde iyileşmeler olduğunu bildirmişlerdir. Sinbiyotik katkılı yemle beslenen grupta (GOS+EnF) büyüme performansı, hayatta kalma oranı ve yem verimliliğin en yüksek oranda olduğunu tespit etmişlerdir.

Balıklarda büyüme performansı ve hayatta kalma oranı üzerine önemli artışları gözlemlenen Grobiyotik A, Previda ve İmmunojen gibi ticari prebiyotikler çalışma yapılan eklembacaklılarda aynı etkiyi göstermemiştir. Anuta ve ark. (2016), beyaz karideslerde ( $L$. vannameı) yaptıkları 35 günlük uygulama sonucunda Previda'nın yeme katılmasinın büyüme ve YDO üzerine herhangi bir etkisinin olmadığını bildirmişlerdir. Benzer şekilde Li ve ark. 
(2009), Grobiyotik A prebiyotiğinin, Miandare ve ark. (2017), farklı dozlarda immunojen ilavesinin beyaz karideslerde büyüme performansı üzerine bir etkisinin olmadığını bildirmişlerdir.

Miandare ve ark. (2017), ve Anuta ve ark. (2016), hayatta kalma oranında bir değişiklik olmadığını bildirmiş fakat $\mathrm{Li}$ ve ark. (2009), hayatta kalma oranında kontrol grubuyla karşılaştırıldığında önemli artışlar görüldüğünü ifade etmiştir.

\section{Prebiyotik Kullanımının Sindirim Enzim aktiviteleri ve Barsak Morfolojisine Etkileri}

Eklembacaklılar, omurgalılarla karşılaştırıldığında basit bir sindirim sistemine sahip olmakla birlikte diğer omurgasızlara göre oldukça komplekstir. Sindirim sistemi; ön barsak (öğütmek için özelleşmiş büyük mide), orta barsak (barsak tüpü, anterior ve posterior orta barsak, seka ve hepatopankreas) ve tuz-su düzenlemesinin yapıldığ son barsaktan oluşur. Sindirim bezi, sindirim enzimlerini salgılar ve sindirim ürünlerinin emilimine yardımcı olur (Mazlum ve ark., 2011; Mazlum ve Yılmaz, 2012; Parrillo ve ark., 2017).

Hepatopankreas, eklembacaklılarda, sindirim, besin emilimi, sindirim enzimlerinin salgılandığı, sentezlendiği, büyüme ve kabuk değişiminde ana enerji kaynağı olarak kullanılan sindirim sisteminin en büyük organıdır (Vogt, 1996). Bu yüzden yemlerdeki aktif maddelerin değerlendirilmesinde önemli bir gösterge olarak kabul edilir. Hepatopankreas vücudun \%2-6’lık kısmını oluşturur. Hepatopankreasın büyüklüğü eklembacaklılarda kronik stresin bir göstergesidir. Aynı zamanda eklembacaklıların yaşam evreleri ve beslenme düzeyleri arasındaki farkları ölçmek için de kullanılır (Eversole ve Mazlum, 2002; Mazlum ve Yilmaz, 2012; Parrillo ve ark., 2017).

Modern su ürünleri yetiştiriciliğinde toplam maliyetin yaklaşık \% 60'ını oluşturan yem, işletmelerde karlılık üzerine önemli bir etkiye sahiptir. Son yıllarda fonksiyonel yem katkı maddeleri kullanılarak balıklarda ve kabuklularda besin sindirilebilirliği ve sindirim enzim aktivitelerinin arttırılması üzerine çalışmalar yapılmaktadır (Miandare ve ark., 2017; Hoseinifar ve ark., 2017). Eklembacaklılarda yapılan çalışmaların çoğu probiyotiklerin sindirim enzim aktiviteleri üzerine pozitif etkilerini içerirken, çok az bir çalışma ise prebiyotiklerin tek başlarına veya probiyotiklerle birlikte verilmesinin etkilerini içermektedir (Miandare ve ark., 2017; Safari ve ark., 2017; Sivasankar ve ark., 2017; Nedaei ve ark., 2019).

Eklembacaklılarda sindirim enzim aktivitesi, beslenme fizyolojisinde önemli role sahiptir. Yüksek enzim aktivitesi besinlerin daha verimli bir biçimde sindirilmesine bağlı olarak daha fazla büyümeye ve kabuk değişimine katkı sağlar (Sang ve ark., 2011; Sumon ve ark., 2018).

Prebiyotiklerin ana kaynağını oluşturan oligosakkaritler, sindirim sistemindeki laktik asit ve kısa zincirli yağ asitlerinin (KZYA) birikimini teşvik eder. $\mathrm{Bu}$ asitlerin mukozal hücre çoğalmasını arttırarak, mukozal yapının iyileşmesine katkı sağladığı öne sürülmüştür (Daniels ve Hoseinifar, 2014). Prebiyotik fermantasyonun sonucu asetat, probiyonat ve bütirat olmak üzere bağırsak enterositleri için önemli bir enerji kaynağı olan KZYA üretilebilmektedir. KZYA'nin, sindirim ve emilimin gerçekleştiği bağırsakta $\mathrm{pH}$ değerini düşürdüğü ve sindirim enzim aktivitelerinde iyileşme sağladığı, bu durumun da yemin sindirilebilme ve emilebilme durumunu arttırdığ 2017a). Ayrica, LAB (Laktobasiller) tarafindan üretilen asitler, minerallerin daha yüksek çözünürlüğünü sağlayarak, metal iyonlarının emilimini de arttirabilmektedirler (Daniels ve Hoseinifar, 2014).

MOS'un sindirim enzim aktiviteleri ve bağırsak histolojisi üzerine etkileri kerevit, karides ve istakozlarda farklı yönleriyle araştırılmış̧ır (Genç ve ark., 2007; Huu ve ark., 2014; Sang ve ark., 2014; Safari ve ark., 2017; Safari ve Paolucci, 2017a; Nedaei ve ark., 2019). Bio-MOS'un sindirim sisteminin histolojisini değiştirerek emilim yüzeyini ve kapasitesini arttırarak geliştirdiği ileri sürülmüştür (Huu ve ark., 2014; Rodriguez ve ark., 2018). Bağışıklık sistemini düzenlediği enzim aktivitesini arttırarak yemlerin daha iyi daha iyi değerlendirilmesine yardımcı olduğu bildirilmiştir (Denev ve ark., 2009). Genç ve ark., (2007), kaplan karidesinde MOS'un hepatopankreas histolojisi üzerindeki etkilerini araştırmış ve hepatopankreas morfolojisi ve dokusunda olumsuz bir etkisinin olmadığını bildirmişlerdir. Bir diğer uygulamada MOS'un Avrupa istakozu larvalarinda (Homarus gammarus) barsak mikrovilluslarının uzunluğunun ve yoğunluğunun artmasına neden olduğu bildirilmiştir (Daniels ve ark., 2010). Yavru dikenli istakozların yemlerine MOS ilavesinin de barsak milim yüzeyini arttırdığı rapor edilmiştir (Sang ve Fotedar, 2010). Rodrigues ve ark. (2018), biyoyumak sistemde yetiştirilen Pasifik beyaz karidesleri ( $L$. vannamei) \%0.12 mannoprotein katkılı yemle beslediğinde barsak villuslarının uzunluk ve genişliğinde artış olduğunu bildirmişlerdir. Sang ve ark. (2014) juvenil siyah kaplan karidesinde ( $P$. monodon) daha düşük konsantrasyonlarda (1-2 $\left.\mathrm{g} \mathrm{kg}^{-1}\right)$ yeme ilave edilen MOS'un epitel kalınlığını ve epidermal hücre yoğunluğunu da arttığı bildirilmişlerdir.

Bio-MOS katkılı (\%0.4) yemle 56 gün beslenen Cherax destructor türü kerevitlerin barsaklarındaki amilaz aktivitesinin kontrol grubuna göre daha 
yüksek bulunduğunu ifade etmişlerdir. Hepatopankreastaki amilaz aktivitesinin, kontrol grubuna göre farklılık göstermediğini, proteaz aktivitesinin ise daha yüksek olduğu bildirmişlerdir. MOS'un eklembacaklılarda enzim aktivitelerini uyarma mekanizması tam olarak araştırılmamıştır. Bununla birlikte, MOS'un kerevitlerde sindirim sistemindeki faydalı bakterilerinin yoğunluğunu arttırarak sindirim enzim aktivitelerinde artış sağladığı, bu artışın da yem değerlendirmeyi iyileştirerek büyümeye katkı sağladığını belirtmişlerdir (Sang ve ark., 2011).

Artemia farklı oranlarda MOS ile zenginleştirilerek $0.5 \mathrm{~g}$ büyüklüğündeki Pasifik beyaz karides ( $L$. vannamei) post larvalarına verildiğinde sindirim enzim aktivitelerinin (amilaz, proteaz, lipaz) kontrol grubuna göre daha yüksek olduğu bildirilmiştir. En önemli artışların $12 \quad \mathrm{mg} \quad \mathrm{L}^{-1}$ ile yapılan uygulamalardan elde edildiği, ayrıca sindirim enzim aktivitelerindeki artışın yeme eklenen MOS konsantrasyonuyla paralellik gösterdiği ifade edilmiştir (Widanarni ve ark., 2018).

Yemlerde farklı prebiyotikler kullanmanın sindirim sistemindeki emilim ve sindirim sürecinde birçok faydaları olduğu gösterilmiştir. MOS ve FOS prebiyotikleri kerevitlere birlikte verildiğinde amilaz, alkalin proteaz, lipaz gibi sindirim enzim aktivitelerindeki artış, tek tek verilmelerinden ve kontrol grubundan oldukça yüksek bulunmuştur. En düşük sindirim enzim aktivitelerinin kontrol ve $4.5 \mathrm{~g}$ FOS/kg yem ilaveli grupta gözlendiğini, en yüksek artışın $2.25 \mathrm{~g} \mathrm{~kg}^{-1}$ MOS ve $1.5 \mathrm{~g} \mathrm{~kg}^{-1}$ FOS ilaveli gruptan elde edildiği bildirilmiştir (Safari ve ark., 2014).

Faydalı bakteriler için bir besin kaynağ ${ }_{1}$ olan prebiyotikler, bazı bakterilerin miktarını arttırarak, sindirim enzim aktivitelerinde iyileşmeye veya vitamin sağlanmasına yardımcı olabilecekleri de ileri sürülmektedir (Hoseinifar ve ark., 2017). Örneğin, FOS, B-fruktosidaz enzimi eksprese eden laktobasiller ve bifidobakteriler tarafindan fermente edilebilir (Daniels ve Hoseinifar, 2014). Oligosakkaritleri fermente edebilen Bacillus spp. türlerinin de enzimler yardımıyla proteaz ve amilaz üreterek proteinlerin ve nişastanın sindirimine yardımcı olduğu bildirilmiştir (Mahious ve ark., 2006). Bu tür eksojen enzimlerin artması, organizma tarafindan endojen enzimlerin üretimini ve enzimlerin aktivitesini arttırılabilir (Zhou ve ark., 2009; Safari ve Paolucci, 2017; Nedaei ve ark., 2019). Sucul eklembacaklılarda bu konuyu ele alan çok az sayıda çalışma vardır; bununla birlikte, tatlısu kerevitlerinde MOS uygulamasının, orta bağırsaktaki amilaz ve hepatopankreasdaki proteaz aktivitesini artirarak sindirim kapasitesini geliştirdiği ve böylece kerevitlerin büyümesi üzerine olumlu etkiler gösterdiği bildirilmiştir (Sang ve ark., 2011).
Astacus kerevitlerinin, farkl dozlarda GOS prebiyotiği ile 97 gün beslendiğinde bir çalışmada sindirim enzim aktiviteleri (ALP ve proteaz aktivitesi) kontrol grubuna göre farklılık gösterdiği ifade edilmiştir. Buna karşıllı \%2-3 GOS katkılı gruplardaki lipaz aktivitesinin, kontrol ve \%1 GOS katkılı gruba göre önemli artış olduğunu göstermişlerdir. Amilaz aktivitesinin ise \%2-3 GOS ilaveli grupta artış gösterdiği, \%1 GOS ilaveli grupta bu artışın görülmediği belirtilmiştir. Yemlere GOS ilavesinin barsaklardaki faydalı bakterilerin kompozisyonunda geçici olarak değişikliğe yol açtığı bildirilmiştir. $\mathrm{Bu}$ yüzden sindirim sistemindeki Laktobasilleri uygun oranda tutabilmek için üretim periyodu boyunca sürekli veya kesintili olarak yemlere GOS prebiyotiğinin katılması önerilmektedir (Nedaei ve ark., 2019).

Safari ve Paolucci (2017a), prebiyotik, probiyotik ve sinbiyotik katkılı yemle 126 gün beslenen Astacus leptodactylus kerevitlerinde (6g) iki farkl sinbiyotiğin (GOS+Enf ve MOS+Enf) sindirim enzim aktiviteleri üzerine etkisini araştırmışlardır. Kerevitlerin sindirim enzim aktivitelerini (alkalin proteaz, lipaz ve amilaz) GOS+Enf ve MOS+Enf ile beslenen gruplarda, kontrol grubuyla karşılaştırıldığında daha yüksek bulmuşlardır. Proteaz ve Lipaz aktivitelerinin de GOS+Enf ve MOS+Enf ile beslenen gruplarda diğer gruplardan önemli oranda yüksek bulunduğunu not etmişlerdir. En yüksek amilaz aktivitesinin GOS+Enf ile beslenen gruplarda görüldüğünü ifade etmişlerdir. MOS ve GOS prebiyotikli yemlerle beslenen kerevitlerde alkaline proteaz, lipaz ve amilaz aktivitelerinin Enf probiyotikli yemlerle beslenen ve kontrol grubundaki kerevitlere göre daha yüksek bulunduğunu belirlemişlerdir.

Safari ve ark. (2017), kerevitlerde sinbiyotik uygulamalara yönelik yaptıkları bir çalışmada sindirim enzimlerinden alkalin proteaz, lipaz ve amilaz enzimlerinin kontrol grubundan daha yüksek olduğunu bildirmişlerdir. Benzer sonuçlar farklı akuatik türler üzerinde yapılan çalışmalarda da (Safari ve Paolucci, 2017a; safari ve Paolucci, 2017b; Hoseinifar ve ark., 2017) elde edilmiştir.

Kısa zincirli yağ asitleri (asetik asit, propiyonik asit ve butirik asit) yetiştiriciliği yapılan türlerde büyüme parametreleri, immun cevap ve hayatta kalma oranı gibi etkilerin ortaya çıkmasında ana faktörler olarak kabul edilmektedirler. (Hoseinifar ve ark., 2017).

Chen ve ark. (2017), asetik asit, propiyonik asit ve bütirik asit, Macrobrachium rosenbergii olarak bilinen dev tatlısu karidesleri için temel kısa zincirli yağ asitleridir. Asetik asit ve bütirik asit düzeylerinin, \%0.4 FOS ile beslenen karideslerde kontrol grubu ve $\% 1$ FOS grupları ile karşılaştırıldığında oldukça yüksek bulunduğu kayıt edilmiştir. Propiyonik asitte ise gruplar arasında 
farklılık bulunmadığı ifade edilmiştir. Yeme ilave edilen FOS oranlarıla asetik asit ve bütirik asit arasında doğrusal bir ilişki tespit edilmediğini de rapaor etmişlerdir.

Hepatopankreasın histopatolojik olarak incelenmesi eklembacaklıların besinsel durumu hakkında bilgi sağlar. Dev tatlısu karideslerinin yemlerine \%0.4 FOS ilavesinin büyüme performansı, kısa zincirli yağ asitleri miktarı ve hepatopankreasın durumunda iyileşme sağladığı bildirilmiştir. Bu yüzden karides yetiştiriciliğinde bu oranın yem katkı maddesi olarak kullanılabileceği önerilmiştir. Daha yüksek oranlarda (\%1-2) FOS ilavesinin ise hepatopankreasta bazı anomalilere ve oksidatif strese yol açabileceği de bildirilmiştir. Örneklemelerin farklı zamanlarda yapilmasıyla (28 ve 56. günler) büyümenin geliştirilmesinde daha detaylı bilgiler elde edilebileceği ifade edilmiştir (Chen ve ark., 2017).

Prebiyotik fermantasyonun sonucunda oluşan kısa zincirli yağ asitleri (asetik asit, propiyonik asit ve bütirik asit) büyüme, immun cevap ve hayatta kalma oranı üzerinde etkili olan ana faktörler oldukları ileri sürülmektedir. Bu kısa zincirli yağ asitlerinin yağ sentezini modüle ederek besin alımında iyileşme sağlayabileceği öne sürülmüştür (Safari ve Paolucci 2017b).

Eklembacaklılarda büyümedeki artış, sindirim sisteminin morfolojisinde meydana gelen değişikliklerle de ilişkilidir (Safari ve ark., 2017; Hoseinifar ve ark., 2017).

Sindirim sistemi mukozal epitel yapısında meydana gelen iyileşmeler, besinlerin emilimi için daha büyük bir yüzey alanı sağlar. Böylece, yem değerlendirme ve büyüme performansında iyileşme sağlar. Sindirimin önemli bir merkezi olan barsaklar, patojenlere veya besinlerden alınan toksik maddelere sürekli maruz kalan en önemli organlardan biridir. $\mathrm{Bu}$ yüzden barsaklarda meydana gelen iyileşme, patojen bakterilere ve çevresel stres faktörlerine karşı bir direnç göstermeye yardımcı olabilmektdedir (Zhang ve ark., 2012; Duan ve ark., 2017a,b).

Miandare ve ark. (2017), 60 gün beyaz karides post larvalarının $(0.55 \mathrm{~g})$ yemlerine farklı oranlarda $(\% 0.5$, $1.0,1.5)$ ticari bir prebiyotik olan İmmunojeni ilavesinin immun gen ekspresyonunu ve sindirim enzim aktivitesini arttırdığını öne sürmüşlerdir. Sindirim enzim aktivitelerinden biri olan amilaz, İmmunojen katkılı gruplar ve kontrol grubunda farklılık gösterdiğini, 30. günün sonunda sadece lipaz aktivitesinde artış izlendiğini, sonunda ise lipaz ve proteaz aktivitesinin İmmunojenli grupta yüksek bulduklarını kayıt etmişlerdir. Proteaz aktivitesinin \%1.5 immunojen katkılı grupta arttığını, lipaz aktivitesinin de, \%1 ve \%1.5 katkılı gruplarda artış gösterdiğini ifade etmişlerdir.

\section{SONUÇ ve ÖNERİLER}

Eklembacaklılarda prebiyotik uygulamaları, balıklarla karşılaştırıldığında araştırmaların yeterli düzeyde olmadığı açıkça görülmekle birlikte, prebiyotik katkılı yemlerin eklembacaklı yetiştiriciliğinde kullanılmasının olumlu etkilerine yönelik bilgiler mevcuttur. Bu durum, krustaseler ile balıklar arasındaki üretim miktarı farkından kaynaklanmaktadır. Bununla birlikte, prebiyotiklerin büyüme performansı, hayatta kalma oranı, bağışıklıkta gelişme, sindirim sistemi morfolojisi, sindirim sistemi mikrobiyotası ve sindirim enzim aktiviteleri üzerine etkilerinin farklı sonuçlar verdiği de belirlenmiştir. $\mathrm{Bu}$ farklılıkların prebiyotiğin kullanım dozajı, veriliş süresi, veriliş şekli, yetiştiricilik parametreleri, üreme, barsak mikrobiyotası, barsak morfolojisindeki farklardan, prebiyotikleri fermente edilebilme yeteneklerindenve canlının hayat evresinin farklı olması gibi çeşitli parametrelerden kaynaklandığı ileri sürülmektedir.

Prebiyotiklerin organizmalarda gözlemlenen bu faydaların ortaya çıkması kültür koşullarından bağımsız ve birbirleriyle etkileşim içerisinde olan birçok faktöre bağlı olduğu için tek bir faktörün etkisini tespit etmek zordur. Bu yüzden prebiyotik uygulamalardan en uygun sonuçları elde etmek için bu faktörleri aydınlatacak daha ileri araştırmalara ihtiyaç duyulmaktadır. Gelecekte prebiyotikler su ürünleri yetiştiricilik sektöründe verimliliği iyileştirebilecektir. Artan kabuklu yetiştiriciliği de uluslararası talepleri karşılayabilecektir.

Kabuklularda prebiyotiklerin etkilerine odaklanılmış kapsamlı çalışmalar yetersiz olmasına rağmen, prebiyotiklerin kabuklularda hayatta kalma, immun durum, hastalık direnci, büyüme performansı ve yem kullanımında iyileşmeler sağladığı gösterilmiştir. Yemlere prebiyotik takviyesiyle elde edilen faydalı sonuçlar daha başarılı kerevit ve karides yetiştiriciliği yapılmasına önemli katkı sağlayacağı düşünülmektedir.

Yetiştiricilik yapılan işletmelerde mikrobiyal çeşitlilik krusteselerin sindirim sistemi mikrobiyotasını ve pre/probiyotiklerin verimliliğini etkileyebilir. Büyük ölçekli üretim yapan eklembacaklı işletmelerinde büyüme yönetimi ve bu yem katkılarının potansiyel kullanımının daha fazla araştırılması gerekmektedir. $\mathrm{Bu}$ yüzden FISH, qPCR ve metagenomik gibi moleküler teknikler kullanılarak, eklembacaklı prebiyotik gibi çeşitli fonksiyonel yem katkı maddelerinin sindirim sistemi içindeki karmaşık mikrobiyal topluluklar, sindirim enzim aktiviteleri ve besin sindirilebilirliği üzerine muhtemel etkilerini ortaya çıkarmak gelecek araştırma alanlarından biri olacaktır.

Ticari olarak yetiştiriciliği yapılan eklembacaklı türlerinde karşılaşılan temel zorluk, büyüme 
performansını ve hastalık direncini optimize ederek canlının sağlığını destekleyici yem formülasyonunun oluşturulmasıdır. Yeni teknikler kullanarak eklembacaklılarda sindirim ve emilim sürecini kolaylaştırmak eklembacaklı yetiştiriciliğinde daha ekonomik ve pratik yem geliştirilmesine katkı sağlayacaktır. Dolayısıyla, sürdürülebilir eklembacaklı endüstrisinin oluşturulmasinda prebiyotik etkilerin farkl boyutlarıyla değerlendirilmesi çok önemli bir değere sahip olacaktır.

\section{KAYNAKLAR}

Aktaş M, Ciğer O, Genç E, Genç MA, Çavdar N 2014 Effects of Mannan Oligosaccharide and Serotonin on Molting, Growth, Body Composition and Hepatopancreas Histology of White Leg Shrimp Litopenaeus vannamei (Boone 1931). Turkish Journal of Fisheries and Aquatic Sciences 14: 205211.

Anuta JD, Buentello A, Patnaik S, Hume ME, Mustafa A, Gatlin DM, Lawrence AL 2016. Effects of Prebiotic Supplementation of a Commercial Prebiotic Previda on survival, growth, immune responses and Gut Microbiota of Pacific White Shrimp, Litopenaeus vannamei. Aquaculture Nutrition, 22: 410-418.

Chen WW, Romano N, Ebrahimi M, Natrah I 2017. The effects of dietary fructooligosaccharide on growth, intestinal short chain fatty acids level and hepatopancreatic condition of the giant freshwater prawn (Macrobrachium rosenbergii) post-larvae. Aquaculture 469: 95-101.

Daniels CL, Merrifield DM, Boothroyd DP, Davies SJ, Factor JR, Arnold KE 2010. Effect of dietary Bacillus spp. and mannan oligosaccharides (MOS) on European lobster (Homarus gammarus L.) larvae growth performance, gut morphology and gut microbiota. Aquaculture 304: 49-57.

Daniels C, Hoseinifar SH 2014. Prebiotic Applications in Shellfish. (Aquaculture Nutrition: Gut Health, Probiotics and Prebiotics John Wiley \& Sons, Ltd, UK: Ed. Merrifield D, Ringo E) 401-414.

Denev S, Staykov Y, Moutafchieva R, Beev G 2009. Microbial ecology of the gastrointestinal tract of fish and the potential application of probiotics and prebiotics in finfish aquaculture, International Aquatic Research) 1: 1-29.

Dong C, Wang J 2013. Immunostimulatory effects of dietary fructooligosaccharides on red swamp crayfish, Procambarus clarkii (Girard), Aquaculture Research, 44: 1416-1424.

Duan Y, Zhang Y, Dong H, Wang Y, Zheng X, Zhang J 2017a. Effect of dietary Clostridium butyricum on growth, intestine health status and resistance to ammonia stress in Pacific white shrimp Litopenaeus vannamei. Fish \& Shellfish Immunology 65: 25-33.
Duan Y, Zhang Y, Dong H, Zheng X, Wang Y, Hua Li, Liu, Q, Zhang J 2017b. Effect of dietary poly-bhydroxybutyrate (PHB) on growth performance, intestinal health status and body composition of Pacific white shrimp Litopenaeus vannamei (Boone, 1931). Fish \& Shellfish Immunology 60: 520-528.

Elshopakey GE, Risha EF, Abdalla OA, Okamura Y, Hanh VD, Ibuki M, Sudhakaran R, Itami T, 2018. Enhancement of immune response and resistance against Vibrio parahaemolyticus in kuruma shrimp (Marsupenaeus japonicus) by dietary supplementation of 8-1,4-mannobiose, Fish and Shellfish Immunology 74: 26-34.

Eversole AG, Mazlum Y, 2002. Comparative fecundity of three Procambarus species. Journal of Shelfish Research, 21(1): 255-258.

FAO. 2018. The State of World Fisheries and Aquaculture 2018 - Meeting the sustainable development goals. Rome. Licence: CC BY-NC-SA 3.0 IGO.).

Genç MA, Yılmaz E, Genç E, Aktas M 2007. Effects of dietary mannan oligosaccharides (MOS) on growth, body composition, and intestine and liver histology of the hybrid tilapia (Oreochromis niloticus $\times O$. aureus). Israeli Journal of Aquaculture - Bamidgeh 59: 10-16.

Genç E, Genç MA, Aktaş M, Bircan-Yıldırım Y, İkizdoğan AT 2011. Su ürünleri yetiştiriciliğinde mannan-oligosakkarit (MOS) kullanımı üzerine Türkiye'de farkındalık yaratma. Süleyman Demirel Üniversitesi Eğirdir $\mathrm{Su}$ Ürünleri Fakültesi Dergisi, 7(1):18-24.

Genç E, Kaya D, Qaranjiki S, Güroy D, Genç, MA 2017. Effects of Different Dietary Oligosaccharides on Growth of Clarias gariepinus in Recirculated Aquaculture System: Preliminary results. I International Symposium on Limnology and Freshwater Fisheries, 4-6 October, Isparta, Turkey.

Genç E, Kaya D 2017. Antibiotic Usage; Aquaculture Awareness. I International Symposium on Limnology and Freshwater Fisheries, 4-6 October, Isparta, Turkey.

Hai VN, Fotedar R, 2009. Comparison of the effects of the prebiotics (Bio-Mos ${ }^{\circledR}$ and B-1,3-D-glucan) and the customised probiotics (Pseudomonas synxantha and $\mathrm{P}$. aeruginosa) on the culture of juvenile western king prawns (Penaeus latisulcatus Kishinouye, 1896). Aquaculture 289, 310-316.

Hoseinifar SH, Zare P, Merrifield DL 2010. The effects of inulin on growth factors and survival of the Indian white shrimp larvae and postlarvae (Fenneropenaeus indicus). Aquaculture Research, 41, e348-e352.

Hoseinifar SH, Zare P, Miandare HK 2015. The effects of different routes of inulin administration 
on gut microbiota and survival rate of Indian white shrimp post-larvae (Fenneropenaeus indicus). Veterinary Research Forum 6 (4): 331 335.

Hoseinifar SH, Dadar M, Ringo E 2017. Modulation of nutrient digestibility and digestive enzyme activities in aquatic animals: The functional feed additives scenario. Aquaculture Research. 1-14.

Huynh TG, Shiu Ya-Li, Nguyen TP, Truong QP, Chen JC, Liu CH, 2017. Current applications, selection, and possible mechanisms of actions of synbiotics in improving the growth and health status in aquaculture: A review Fish \& Shellfish Immunology 64: 367-382.

Huynh TG, Cheng AC, Chi CC, Chiu KH, Liu CH 2018. A synbiotic improves the immunity of white shrimp, Litopenaeus vannamei: Metabolomic analysis reveal compelling evidence, Fish and Shellfish Immunology 79: 284-293.

Huu HD, Jones CM 2014. Effects of dietary mannan oligosaccharide supplementation on juvenile spiny lobster Panulirus homarus (Palinuridae) Aquaculture 432: 258-264.

Li P, Wang X, Murthy S, Gatlin DM, Castille FL and Lawrence AL 2009 Effect of dietary

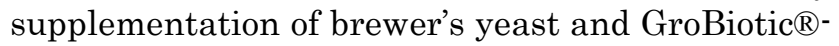
A on growth, immune responses, and low-salinity tolerance of Pacific white shrimp Litopenaeus vannamei cultured in recirculating systems. Journal of Applied Aquaculture 21: 110-119.

Li Y, Liu H, Dai X, Li J, Ding, F 2018. Effects of dietary inulin and mannan oligosaccharide on immune related genes expression and disease resistance of Pacific white shrimp, Litopenaeus vannamei, Fish and Shellfish Immunology 76: 7892.

Luna-González, A, Almaraz-Salas JC, FierroCoronado JA, Flores-Miranda MDC, and GonzálezOcampo HA, Peraza-Gómez V., 2012. The prebiotic inulin increases the phenoloxidase activity and reduces the prevalence of WSSV in whiteleg shrimp (Litopenaeus vannamei) cultured under laboratory conditions. Aquaculture 362-363: 2832.

Mazlum E, Yılmaz E, Genç MA, Güner Ö 2011. A preliminary study on the use of manan oligosaccharides (MOS) in freshwater crayfish, Astacus leptodactylus Eschscholtz, 1823 juvenile diets. Aquaculture International. 19: 111-119.

Mazlum Y, Yllmaz E, 2012 Kerevitlerin Biyolojisi ve Yetiştiriciliği. Mustafa Kemal Üniversitesi Yayınları, Hatay sayı 34 s.120.

Miandare HK, Mirghaed AT, Hosseini M, Mazloumi N, Zargar A, Nazari S 2017. Dietary Immunogen ${ }^{\circledR}$ modulated digestive enzyme activity and immune gene expression in Litopenaeus vannamei post larvae. Fish \& Shellfish Immunology 70: 621-627.
Mona MH, Rizk ST, Salama WM, Younis MN 2015. Efficacy of probiotics, prebiotics, and immunostimulant on growth performance and immunological parameters of Procambarus clarkii juveniles, The Journal of Basic \& Applied Zoology 69: $17-25$.

Motamedi-Sedeh F, Afsharnasab M, Heidarieh M, Tahami SM 2017. Protection of Litopenaeus vannamei against white spot syndrome virus by electron-irradiated inactivated vaccine and prebiotic immunogen Radiation Physics and Chemistry 130: 421-425.

Nedaei S, Noori A, Valipour A, Asghar Khanipour AA, Hoseinifar SH 2019. Effects of dietary galactooligosaccharide enriched commercial prebiotic on growth performance, innate immune response, stress resistance, intestinal microbiota and digestive enzyme activity in Narrow clawed crayfish (Astacus leptodactylus Eschscholtz, 1823). Aquaculture 499: 80-89.

Parrillo L, Coccia E, Volpe MG, Siano F, Pagliaruloa C, Scioscia E, Varricchio E, Safari O, Eroldogan T, Paolucci M, 2017. Olive mill wastewater-enriched diet positively affects growth, oxidative and immune status and intestinal microbiota in the crayfish, Astacus leptodactylus. Aquaculture 473: 161-168.

Partida-Arangure BA, Luna-González A, FierroCoronado JA, Flores-Miranda MDC and GonzálezOcampo HA 2013. Effect of inulin and probiotic bacteria on growth, survival, immune response, and prevalence of white spot syndrome virus (WSSV) in Litopenaeus vannamei cultured under laboratory conditions. African Journal of Biotechnology, 12(21): 3366-3375.

Ringo E, Olsen RE, Gifstad TO, Dalmo RA, Amlund H, Hemre GI, Bakke AM 2010. Prebiotics in aquaculture: a review, Aquaculture Nutrition, 16(2): 117-136.

Roberfroid M 2007. Prebiotics: The Concept Revisited. The Journal of Nutrition, Effects of Probiotics and Prebiotics, 137: 830-837.

Rodrigues MS, Bolivar N, Legarda EC, Guimaraes AM, Guertler C, Santo CME, Mourino JLP, Seiffert WQ, Fracalossi DM, Vieira FN 2018, Mannoprotein dietary supplementation for Pacific white shrimp raised in biofloc systems, Aquaculture 488: 90-95.

Rungrassamee W, Kingcha Y, Srimarut Y, Maibunkaew S, Karoonuthaisiri N, Visessanguan W 2014. Mannooligosaccharides from copra meal improves survival of the Pacific white shrimp (Litopenaeus vannameI) after exposure to Vibrio harveyi, Aquaculture, 434, pp. 403-410.

Safari O, Shahsavani D, Paolucci M, Atash MMS 2014. Single or combined effects of fructo- and mannan oligosaccharide supplements on the growth performance, nutrient digestibility, 
immune responses and stress resistance of juvenile narrow clawed crayfish, Astacus leptodactylus leptodactylus Eschscholtz, 1823, Aquaculture 432: 192-203.

Safari O ve Paolucci M 2017a. Effect of in vitro selected synbiotics (galactooligosaccharide and mannanoligosaccharide with or without Enterococcus faecalis) on growth performance, immune responses and intestinal microbiota of juvenile narrow clawed crayfish, Astacus leptodactylus leptodactylus Eschscholtz, 1823. Aquaculture Nutition 24(1): 247-259.

Safari O ve Paolucci M 2017b. Modulation of growth performance, immunity, and disease resistance in narrow-clawed crayfish, Astacus leptodactylus leptodactylus (Eschscholtz, 1823) upon synbiotic feding, Aquaculture 479: 333-341.

Safari O, Paolucci M, Motlagh HA 2017. Effects of synbiotics on immunity and disease resistance of narrowclawed crayfish, Astacus leptodactylus leptodactylus (Eschscholtz, 1823), Fish \& Shellfish Immunology 64: 392-400.

Sang HM, Ky LT, Fotedar R 2009. Dietary supplementation of mannan oligosaccharide improves the immune responses and survival of marron, Cherax tenuimanus (Smith, 1912) when challenged with different stressors, Fish \& Shellfish Immunology 27: 341-348.

Sang HM, Fotedar R 2010. Effects of mannan oligosaccharide dietary supplementation on performances of the tropical spiny lobsters juvenile (Panulirus ornatus, Fabricius 1798). Fish \& Shellfish Immunology 28: 483-489.

Sang HM, Fotedakar R, Filer K 2011. Effects of dietary mannan oligosaccharide on the survival,growth, immunity and digestive enzyme activity of freshwater crayfish, Cherax destructor Clark (1936). Aquaculture Nutrition 17:e629-e635.

Sang HM, Kien NT, Thanh Thuy NT 2014. Effects of dietary mannan oligosaccharide on growth, survival, physiological, immunological and gut morphological conditions of black tiger prawn (Penaeus monodon Fabricius 1798). Aquaculture Nutrition 20: 341-348.
Sivasankar P, John KR, George MR, Anushalini SV, Kaviarasu D, Petchimuthu M 2017. Prophylactics in shrimp aquaculture health management: A review ,Journal of Entomology and Zoology Studies 5(4): 1049-1055.

Sumon MS, Ahmmed F, Khushi SS, Ahmmed MK, Rouf MA, Chisty MAH, Sarower MG 2018. Growth performance, digestive enzyme activity and immune response of Macrobrachium rosenbergii fed with probiotic Clostridium butyricum incorporated diets. Journal of King Saud University - Science 30: 21-28.

Vogt G, 1996. Morphology and physiology of digestive epithelia in Decapod crustaceans. Pfltigers Arch Eur J Physiot 431[Suppl]:R239-R240.

Wang G, Zhou W, Huang Y, Huang X, Liu and Dong, $\mathrm{S}$ 2010. Effects of xylooligosaccharide on grow, body composition and non-specific immunity in Litopenaeus vannamei. Freshwater Fish., 40: 5558.

Widanarni T, Yuhana M, Ekasari J 2018. Dietary Mannan Oligosaccharides Positively Affect the Growth, Digestive Enzyme Activity, Immunity and Resistance Against Vibrio harveyi of Pacific White Shrimp (Litopenaeus vannamei) Larvae. Turkish Journal of Fisheries and Aquatic Sciences 19 (4) 271-278.

Yazıcı M, Candan A, 2006. Levrek balıklarında (Dicentrarchus labrax) Pasteurellosis'e karşı alternatif aşlama yöntemleri üzerine bir araştırma. Su Ürünleri Dergisi, 20: 1-16.

Yazıcı M, 2017. Bazı Prebiyotiklerin Yetiştiriciliği yapılan balıklarda bağışıklık ve Hastalık direnci üzerine etkileri. Yunus Araştırma Bülteni 17 (4): 429-449.

Zhang J, Liu Y, Tian L, Yang H, Liang G, Xu D 2012. Effects of dietary mannan oligosaccharide on growth performance, gut morphology and stress tolerance of juvenile Pacific white shrimp, Litopenaeus vannamei, Fish \& Shellfish Immunology 33: 1027-1032.

Zhou Q, Li K, Jun X, Liu B 2009. Role and functions of beneficial microorganisms in sustainable aquaculture. Bioresource Technology 100: 37803786 . 